\title{
Improving fetal dystocia management using simulation in Senegal: midterm results
}

\author{
Mamour Gueye $^{1,2 *}$, Philippe Marc Moreira ${ }^{1,2}$, Moussa Diallo ${ }^{1,2}$, Omar Gasama ${ }^{1,2}$, \\ Mohamed Diadhiou ${ }^{1,2}$, Mame Diarra Ndiaye Gueye ${ }^{1,2}$, Serigne Modou Kane Gueye ${ }^{1,2}$, \\ Marie Edouard Faye Dieme ${ }^{1,2}$, Abdoul Aziz Diouf ${ }^{1,2}$, Mouhamadou Mansour Niang ${ }^{1,2}$, \\ Dior Dieng ${ }^{3}$, Ousmane Ndiaye ${ }^{3}$, Alassane Diouf ${ }^{1,2}$, Jean Charles Moreau ${ }^{1,2}$
}

\begin{abstract}
${ }^{1}$ Department of Obstetrics and Gynecology, EPS Aristide Le Dantec Avenue Pasteur, BP 3001, Dakar, Senegal
${ }^{2}$ Training and Research Center in Reproductive Health, BP 3001, Dakar, Senegal

${ }^{3}$ Department of Pediatrics, Abass NDAO Hospital Center, Dakar, Senegal
\end{abstract}

Received: 19 October 2017

Accepted: 11 December 2017

*Correspondence:

Dr. Mamour Gueye,

E-mail: mamourmb@yahoo.fr

Copyright: () the author(s), publisher and licensee Medip Academy. This is an open-access article distributed under the terms of the Creative Commons Attribution Non-Commercial License, which permits unrestricted non-commercial use, distribution, and reproduction in any medium, provided the original work is properly cited.

\begin{abstract}
Background: Maternal mortality, which constitutes the extreme point of the existing inequality between women in poor and rich countries, remains very high in Africa south of the Sahara. The objective of this study was to introduce a new training approach in Emergency Obstetric and Neonatal Care (EmONC) entered in Senegal to strengthen the skills of healthcare providers.

Methods: The approach was based on the skills training using the so-called "humanist" method and "lifesaving skills". Simulated practice took place in the classroom through thirteen clinical stations summarizing the clinical skills on EmONC. The evaluation was done in all phases and the results were recorded in a database to document the progress of each learner.

Results: With this approach, 432 providers were trained in 10 months. The increase in technical achievements of each participant was documented through the database. The combination of training based on the model "learning by doing" has ensured learning and mastering all EmONC skills and reduced missed learning opportunities as observed in former EmONC trainings.

Conclusions: The impact of training on EmONC indicators and the introduction of this learning modality in basic training are the two major challenges in terms of prospects.
\end{abstract}

Keywords: Dystocia, Emergency obstetric care, Training, Training models

\section{INTRODUCTION}

Maternal mortality, which constitutes the extreme point of the existing inequality between women in poor and rich countries, remains very high in Africa south of the Sahara. It can be up to 1000 per 100,000 live births. While the majority of pregnancies and births occur without incident, about $15 \%$ of all pregnant women will experience a potentially life-threatening complication requiring skilled care; some will need a major obstetric intervention to survive. The introduction of the concept of Emergency Obstetric and Neonatal Care (EONC) will contribute to the reduction of maternal and infant mortality and morbidity by better monitoring of pregnancy, childbirth and postpartum, early detection and appropriate treatment of the morbid factors and pathologies encountered, hence the need to develop the skills of health workers in this field. Conventional 
training in EONC often combines theoretical training in the classroom with the stage at the hospital stage with limitations linked to the fact that emergencies are not programmable for learning during the training session. The aim of this work is to present an innovative approach to continuing education in EONC, focusing on the price of fetal dystocia in Senegal, the general principle of which was to master essential gestures in simulated classroom practice before practice in a real situation in maternity, all supported by a continuous evaluation of the performance of the provider.

The approach was based on competencies using the "humanist" training modeled by JHPIEGO and the lifesaving skills developed since 2007 by the Liverpool School of Tropical Medicine and the Royal College of Obstetricians and Gynecologists. ${ }^{1,2}$

\section{METHODS}

\section{Preliminaries}

The aim of this training course was to prepare participants for the 5 major causes of maternal mortality (bleeding, infections, high blood pressure, dystocia and complications of abortion) and then neonatal asphyxia.

It took place in two phases: a first phase of six to ten days in the form of a seminar in the classroom and a second phase in the form of two formative supervisory visits lasting two days at the provider's site. After an evaluation of the training needs of the EONC, a literature search made it possible to develop standardized tools (trainer's manual, learner's booklet, learning sheets and checklist) that have been validated by the Ministry of Education, health and development partners (Belgian Technical Cooperation, UNFPA). The trainers were gynecologists and obstetricians, teachers at the University of Dakar, who were trained as trainers in a Senegalese institution, capitalizing on a large experience of training based on competence in some decade French-speaking countries the Center for Training, Research and Advocacy in Reproductive Health. Participants were midwives and nurses working in maternity.

\section{Pedagogic acquisition method}

The approach was based on competencies using the "humanist" training modeled by JHPIEGO and the lifesaving skills developed since 2007 by the Liverpool School of Tropical Medicine and the Royal College of Obstetricians and Gynecologists. ${ }^{1,2}$

The simulated practice took place in the classroom through clinical stations in which the different clinical skills related to the EONC were developed. At each station, an initial assessment of the participant was carried out, which enabled him to assess his level of competence. A trainer demonstrated competence and then mentored the participant to the master's level. Each participant had to validate the skill on one station before moving on to the next. A leaflet describing the steps of each clinical procedure allowed the learner to follow the demonstration, to practice and to appreciate its progression. We present here the results of the competences relating to the management of dystocia. These include the management of the dystocia of the seat, the management of shoulder dystocia and the management of the delivery of the second twin in transverse presentation. At the end of the training in the classroom, two formative supervision visits on the site of each provider made it possible to complete the training in real situations. This article reports the results of the first phase, the visits to the site have not yet been completed.

\section{Pedagogic equipment}

Two teaching manuals were used: a reference manual published by the World Health Organization and a trainer's guide developed and validated by the Ministry of Health. Numerous anatomical models (Figure 1) as well as equipment and consumables were used to make the clinical situations of the different stations as realistic as possible.

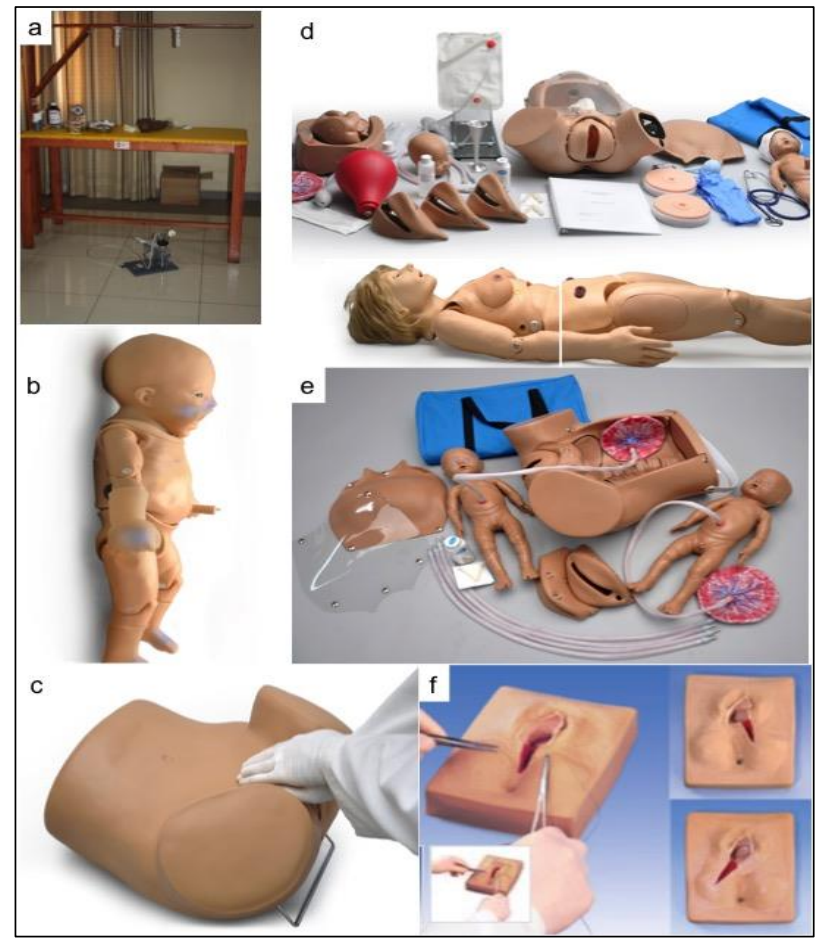

a: Neonatal resuscitation table of artisanal manufacture; b: Newborn resuscitation model (Gaumard); c: Anatomical model for manual aspiration intrauterine; d: Set of simulation and treatment of postpartum hemorrhage; e: Birthing model and articulated fetus; f: Episiotomy repair model (3B Scientific)

Figure 1: Simulation models.

\section{Assessment method}

The theoretical evaluation consisted of the administration of a prior questionnaire and a mid-stage questionnaire. A 
performance of at least $85 \%$ was required. The practical evaluation used a checklist and included an initial assessment, a mid-term evaluation and a final evaluation for each competency.

A computerized database generating graphs was filled in as the training went on. During the formative supervision on the provider's site, the trainer, using the same checklists, assessed the performance of the provider in real-life situations, thus allowing the database to be filled. The claimant was declared competent after passing the theoretical assessment and practical classroom assessments and during the two formative supervision visits.

\section{RESULTS}

A total of 432 providers were trained according to this approach between July and December 2015 after 25 training sessions. Means for initial assessments of the 432 participants for head birth, shoulder dystocia and internal maneuvering were $27.7 \%, 17.1 \%$, and $16.2 \%$, respectively. The distribution of participants is shown in Figure 2.

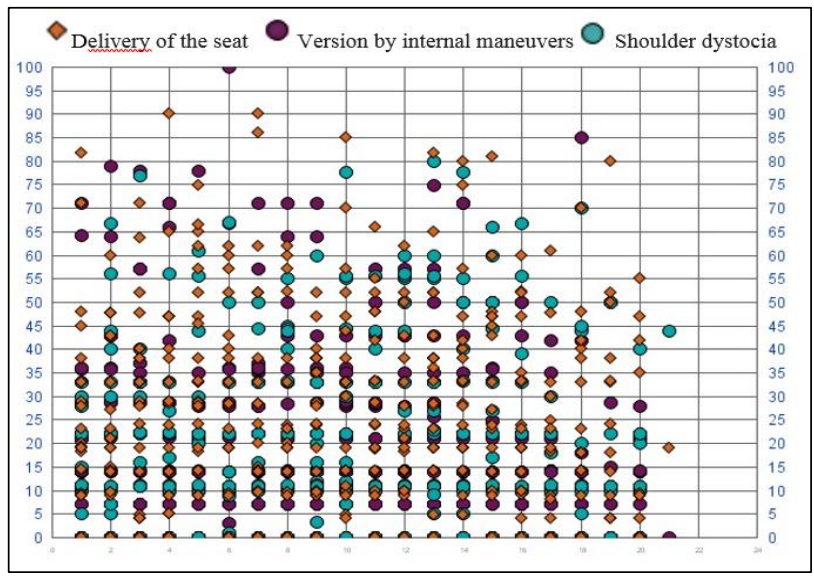

Figure 2: Breakdown of participants according to the results of the initial assessment.

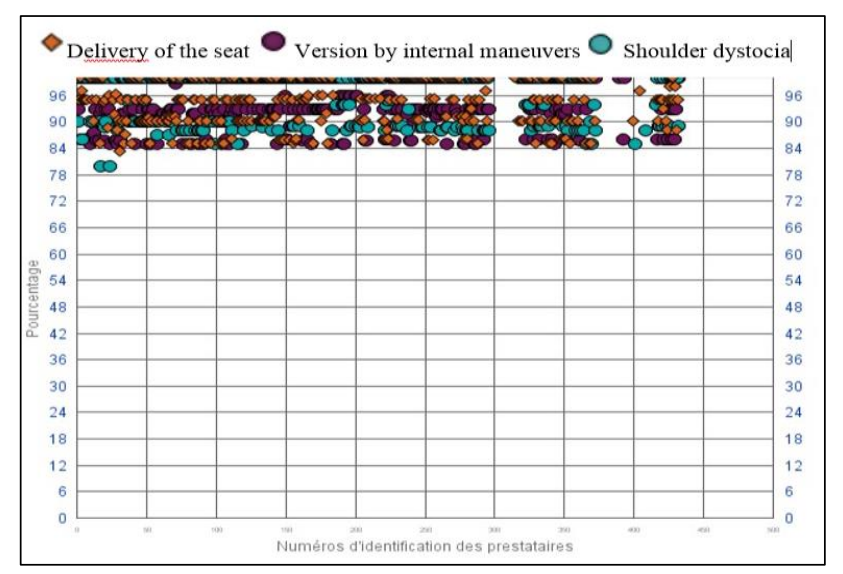

Figure 3: Breakdown of participants according to the results of the mid-term evaluation.
The average of $85 \%$ deemed to be minimal to validate competence was reached by almost all participants in the mid-term evaluation with an average of $91.6 \%, 94.7 \%$ and $93.7 \%$ for the 3 competencies respectively. Only those participants who did not validate a competency at the mid-term evaluation (score $<85 \%$ ) resumed the training after a training session. They validated the competency upon obtaining a mark of $85 \%$ or more. Figure 3 shows the results of the final evaluation.

\section{DISCUSSION}

Obstetricians and midwives face extreme emergencies that need to be managed quickly, efficiently and in a team environment. These situations, which are often rare, are serious and must be dealt with by experienced staff. Yet, because of the increasing number of learners and the scarcity of teachers in maternity hospitals, exposure to critical situations has become less frequent. In this study, we identified the inability of some providers to identify some obstetric emergencies such as arm lift and shoulder dystocia.

Management was affected by the lack of technical skills, but also the importance of interpersonal and interdisciplinary communication problems. Shoulder dystocia is a situation where recognized maneuvers can avoid associated complications, which is why simulation training seems ideal for dealing with this situation. ${ }^{4}$

Several studies have shown an improvement in the practice of these exercises after simulation training. ${ }^{5-7}$ Improvement in management persisted six to twelve months after training. ${ }^{8}$ A retrospective study assessed the presence of obstetric and neonatal complications in shoulder dystocia before nd after eight-year training, not only with improved use of post-training maneuvers but also with improved outcomes with a statistically significant decrease in neonatal lesions at birth. ${ }^{9}$ The raising of the arms is a contingency which is not exceptional and often comes but not always complicate an inopportune maneuver of traction too early or outside the uterine contraction.

The subacromial-acromial diameter often measures more than $12 \mathrm{~cm}$. It must be diminished by the successive lowering of the arms by the maneuver of Lovset. This maneuver, in our opinion, must be known to all midwives in our country where the birth of the fetus in the breech presentation is part of their prerogatives. Her mastery contributes to the reduction of maternal-fetal and neonatal morbidity and mortality in our countries.

The head retention at the middle and lower strains is most often encountered in the primipara. It is far from negligible. When it occurs, the midwife often tends to shoot and this in an untimely manner. The observation of the beneficiaries during the initial evaluation enabled us to make this sad observation. Understanding the bending mechanism and therefore the reduction of diameters 
makes it easy to unblock the head and finish the delivery. All the providers have been able to apply this Mauriceau maneuver which is very easy to learn and master. In case of twin pregnancy with second twin in transverse presentation, caesarean section can be proposed. However, an operating room is not available in all health centers and the sanitary evacuation system is not performing well in our country. This contributes to maternal and neonatal morbidity, hence the need to cope with this situation.

A version by internal maneuvers followed by an extraction of the seat will allow, by grasping the two feet of the second twin, to consider its birth in good conditions especially since the twins are often of small weight.

This training made it possible to understand that the providers apprehend this obstetric maneuver but with a humanistic practice using the anatomical models, the doubts are quickly dispelled, and the competence quickly acquired from an average of $16.2 \%$ at the initial evaluation to 93,7 to mid-term evaluation.

\section{CONCLUSION}

The simulated practice ensures the learning and mastery of all the skills of the SONU and minimizes the risks during the practice in the patients. The main challenge remains twofold: to document the impact of this training on emergency obstetric care indicators and to integrate this training modality into basic training (medical school, midwifery school).

\section{Funding: No funding sources} Conflict of interest: None declared

Ethical approval: The study was approved by the Institutional Ethics Committee

\section{REFERENCES}

1. Sullivan R. Clinical Training Competencies for Reproductive Health Professionals. JHPIEGO Corporation: Baltimore, Maryland; 1995.

2. van den Broekn N. Lifesaving skills manual. RCOG, London. 2007.

3. World Health Organization. Management of complications of pregnancy and childbirth: a guide for the midwife and physician. Geneva. 2004.

4. WHO, UNFPA, UNICEF, Bank W. Managing complications in pregnancy and childbirth. WHO/RHR/00.7, 2000. Available at http://apps.who.int/iris/bitstream/10665/42644/1/924 1545879.pdf

5. Elbourne DR, Prendiville WJ, Carroli G, Wood J, McDonald S. Prophylactic use of oxytocin in the third stage of labour. In: The Cochran Library; Oxford. Update Software. 2003;3.

6. Prendiville WJ, Elbourne D, McDonald S. Active versus expectant management in the third stage of labour. In: The Cochrane Library. Oxford: Update Software; 2003;3.

7. Joy SD, Sanchez-Ramos L, Kaunitz AM. Misoprostol use during the third stage of labor. Int $\mathbf{J}$ Gynecol Obstet. 2003;82:143-52.

8. Maslovitz S, Barkai G, Lessing JB, Ziv A, Many A. Recurrent obstetric management mistakes identified by simulation. Obstet Gynecol. 2007;109:1295-300.

9. Birch L, Jones N, Doyle PM. Obstetric skills drills: Evaluation of teaching methods. Nurse Educ Today. 2007;27:915-22.

Cite this article as: Gueye M, Moreira PM, Diallo M, Gasama O, Diadhiou M, Gueye MDN, et al. Improving fetal dystocia management using simulation in Senegal: midterm results. Int J Reprod Contracept Obstet Gynecol 2018;7:52-5. 